Bond University

Research Repository

\title{
Diagnosis of heart failure in primary care
}

Hobbs, F. D. R.; Doust, J.; Mant, J.; Cowie, M. R.

Published in:

Heart

DOI:

10.1136/hrt.2007.139402

Licence:

CC BY-NC

Link to output in Bond University research repository.

Recommended citation(APA):

Hobbs, F. D. R., Doust, J., Mant, J., \& Cowie, M. R. (2010). Diagnosis of heart failure in primary care. Heart, 96(21), 1773-1777. https://doi.org/10.1136/hrt.2007.139402

\section{General rights}

Copyright and moral rights for the publications made accessible in the public portal are retained by the authors and/or other copyright owners and it is a condition of accessing publications that users recognise and abide by the legal requirements associated with these rights.

For more information, or if you believe that this document breaches copyright, please contact the Bond University research repository coordinator. 


\title{
Diagnosis of Heart Failure in Primary Care
}

\author{
Hobbs FDR*, Doust J ^^ Mant J^^, Cowie MR** \\ * Primary Care Clinical Sciences, University of Birmingham, B15 2TT \\ ^ Faculty of Health Sciences and Medicine, Bond University, Australia, QLD 4229 \\ ^^ Department of Primary Health Care, University of Cambridge \\ ** National Heart \& Lung Institute, Imperial College, London SW3 6LY
}

Corresponding Author:

Professor FDR Hobbs f.d.r.hobbs@bham.ac.uk

Word Count: 21,048 (excluding summary and appendices) 


\section{Introduction}

Heart failure is a syndrome resulting from a structural or functional cardiac disorder. For a diagnosis of heart failure to be made, there should be symptoms or signs, such as breathlessness, effort intolerance or fluid retention, together with objective evidence of cardiac dysfunction.

Heart failure is an increasingly important chronic disease syndrome, associated with poor prognosis, poor quality of life for patients, and high healthcare costs. ${ }^{1, w 2}$ In the general population, where all grades of heart failure are represented, 5 -year mortality is around $42 \%,{ }^{3}$ but where the diagnosis is established during a hospital admission 5 year mortality is between $50-75 \%$, w5 although the prognosis has improved in the past ten years.

\section{Prevalence and incidence of heart failure}

Studies including objective assessment of left ventricular (LV) function, usually echocardiography, indicate a prevalence of left ventricular systolic dysfunction (LVSD) of $2.9 \%$ in patients under $75^{6}$ and up to $7.5 \%$ in 75 to 84 year olds. ${ }^{\text {w7 }}$ In the largest recent prospective evaluation of heart failure in the community, definite heart failure was found in $2.3 \%(95 \% \mathrm{Cl} 1.9-2.8)$ of the population, with left ventricular ejection fraction (LVEF) less than $40 \%$ in $41 \%$ cases. However, if the LVEF cut off was set at under $50 \%$ rather than $40 \%$, now advocated in some guidelines, $3.1 \%(95 \% \mathrm{Cl} 2.6 \%-3.7 \%)$ of people aged 45 or over were defined as having heart failure. ${ }^{8}$

Estimates on heart failure incidence are less available, and vary from $0.9-2.2^{9}$ per 1000 females (4574) per year and 1.6-4.6 men (45-74) per 1000 population per year. Incidence rises rapidly in the elderly, with $1 \%$ of men per year developing heart failure after 75 and almost $2 \%$ per year in over 85s.

The typical primary care physician, caring for 2000 patients, is likely to have 40-50 patients with heart failure (more if population is elderly), and to have 5 or so new cases of heart failure diagnosed 
each year, with the diagnosis being suspected in perhaps 3 times as many. The syndrome is, therefore, relatively common but not so frequent that the individual practitioner will become expert in diagnosis. Clear guidance is needed on which clinical features and combination of investigations is best to rule out or rule in heart failure in patients with new symptoms.

\section{Burden of heart failure on healthcare systems}

Chronic heart failure remains one of the most costly conditions to manage: the syndrome is common, it frequently results in hospital admission, admissions are long, and re-admission is frequent particularly where chronic disease management programmes are not running (nearly $25 \%$ of patients are readmitted within 12 weeks of discharge). ${ }^{10}$ As a consequence, heart failure accounts for around $2 \%$ of total healthcare expenditure in most developed countries.

\section{Good diagnosis is the cornerstone of good management}

There is a huge evidence base for therapies that improve morbidity, global quality of life, and mortality in all grades of heart failure due to LVSD, ${ }^{11,12}$ and can delay LVSD progression to symptomatic heart failure. ${ }^{\text {w13 }}$ Despite this extensive evidence, heart failure remains sub-optimally diagnosed and treated in many countries. ${ }^{\text {w14 }}$ An essential element for treatment success is the reliable and precise diagnosis of heart failure.

\section{Diagnostic issues in heart failure}

The evaluation of patients with suspected heart failure entails determining more than just whether the syndrome is present or not. It is important to identify the underlying cardiac pathologies, exacerbating or precipitating factors, and the whole body's response to the cardiac dysfunction including particularly renal function. Guidelines for the evaluation and management of heart failure have been published by professional societies in North America (American College of Cardiology/American Heart Association (ACC/AHA) ${ }^{15}$ and Consensus Recommendations ${ }^{\text {w16 }}$ ) and Europe (European Society of Cardiology). ${ }^{17}$ The latter state that the diagnosis of heart failure is 
justified when there are typical signs and symptoms of heart failure and myocardial dysfunction, confirmed by the objective evidence of cardiac dysfunction at rest. In case of diagnostic uncertainty, a clinical response to treatment directed at heart failure is helpful in establishing the diagnosis (Table 1). Simple and reliable diagnostic procedures are very important for primary care physicians, who are responsible for the early diagnosis of heart failure and implementation of adequate therapy in most healthcare systems.

\section{Current NI CE guidance on diagnosing heart failure}

The National Institute for Health and Clinical Excellence (NICE) guideline on chronic heart failure for primary and secondary care in England recommends that patients with suspected heart failure should have an electrocardiograph (ECG) and/or B-type natriuretic peptide (BNP or NT-proBNP) assay performed. ${ }^{18}$ If both are normal, then heart failure is unlikely, and an alternative diagnosis to explain the symptoms should be considered. If either is abnormal, then the patient should have an echocardiogram, or other imaging test, to confirm underlying cardiac dysfunction. (Figure 1) This guidance was based on the high sensitivity of both plasma BNP and the ECG, and the result of a health economic analysis that demonstrated that the cost per life year gained through echocardiography is dependent upon the proportion of patients referred for echocardiography in whom the diagnosis of heart failure is confirmed.

However, current diagnosis of heart failure in primary care is often inaccurate. In one recent UK study, only $34 \%$ of patients with an existing clinical label of heart failure in routine general practice records had this diagnosis confirmed at echocardiography and review. ${ }^{19}$

There have been seven recent systematic reviews relevant to the diagnosis of heart failure in primary care. Three covered all symptoms, signs and diagnostic tests, ${ }^{18,20, w 21}$ three concerned BNP alone, ${ }^{22, w 23, w 24}$ and one was a review of the accuracy of the 12 lead ECG. ${ }^{25}$ 


\section{Symptoms and signs}

Individual symptoms (such as breathlessness, fatigue, exercise intolerance and fluid retention) and signs (such as resting tachycardia, raised jugular venous pressure (JVP), displaced apex beat, third heart sound) are generally weak predictors of heart failure, with poor reliability, and little agreement between clinicians on their presence or absence, even amongst specialists.

In a recent systematic review, a number of symptoms were reasonably specific, including a history of myocardial infarction ( $89 \%$ specificity), orthopnoea (89\%), cardiomegaly ( $85 \%$ ), added heart sounds (99\%), lung crepitations (81\%), and hepatomegaly (97\%) (Table 2). However, in primary care, the most useful symptoms/signs in diagnosis have high sensitivity, since this might enable the clinician to rule out heart failure if the symptom/sign was absent, without the need to refer for further investigation. Dyspnoea is the only clinical feature that comes close to this ideal with a sensitivity of $87 \%$. In practice this symptom is present in the majority of patients in whom heart failure is suspected, with a frequency as high as $95 \%$ in one of the datasets. Nevertheless, a sensitivity of $87 \%$ is not high enough on its own to rule out heart failure if dyspnoea is absent.

\section{I nvestigations}

Both ECG $25, w 26, w 27$ and BNP w21,22,w23 have high sensitivity for heart failure, and so are good tests at ruling out the diagnosis (Table 3). UK based studies restricted to use of ECG in primary care however, give a more mixed picture on the value of ECG, with sensitivity in one study as low as $73 \% .{ }^{25}$ These differences may relate to both differences in population characteristics, and to the skill of the practitioner interpreting the ECG. Similarly, while the chest x-ray may show evidence of heart failure (e.g. cardiomegaly, pulmonary vascular congestion), it is not a good independent predictor, and is of most value in identifying alternative causes of symptoms such as lung disease or pleural effusion. 
In a review of four studies that evaluated the diagnostic accuracy of the resting ECG in the specific context of referral from primary care to echocardiographic services, sensitivity of ECG varied from $73 \%$ to $91 \%$, and the authors concluded that the ECG was an inadequate screening tool. ${ }^{25} \mathrm{~A}$ review of the diagnostic accuracy of natriuretic peptides and ECG in the diagnosis of LVSD found similar diagnostic accuracy between ECG, BNP and NT-proBNP and no value from combining BNP with ECG. ${ }^{28}$ A recent systematic review confirmed that adding ECG to clinical features plus plasma BNP result did not improve the accuracy of diagnosis. ${ }^{20}$

It is likely that BNP is a more accurate test for heart failure than it is for LVSD. Indeed, a recent systematic review of BNP studies concluded that while BNP is useful for excluding heart failure, it is more limited for ruling out systolic dysfunction, with an AUC of 0.93 for heart failure but only 0.75 for systolic dysfunction. ${ }^{29}$ There is no evidence of any significant differences in test performance between BNP and NT-proBNP. ${ }^{28,29}$ Other recent reviews of BNP have confirmed its value as a 'rule out' test for heart failure. ${ }^{\text {w30,w31,w32 }}$

Echocardiography is the most readily available 'reference standard' investigation for LVSD and valve disease. Assessment of diastolic dysfunction can also be made on echocardiography, ${ }^{33}$ but the interpretation of the findings may be difficult, particularly in the elderly and in patients with atrial fibrillation (up to $30 \%$ of new cases of heart failure in most series). In practice today, 'normal ejection fraction' ('preserved systolic function', 'diastolic' or 'non-systolic') heart failure often remains a diagnosis of exclusion. Echocardiography after a plasma BNP test has been performed is an attractive option, particularly if the supply of echocardiography is limited or access is slow, though appropriate cut points for BNP (or NT-proBNP) are then needed.

\section{Role of clinical decision rules in the work up of patients with suspected heart failure}

There are several well developed heart failure diagnostic tools which combine the results of different symptoms/signs and investigations. Mosterd et al applied criteria from six established HF scores 
including Framingham, Walma and Boston to a sample of 54 participants in the population-based Rotterdam study. ${ }^{34}$ Most showed high utility to detect definite heart failure with Areas Under the Receiver Operated Characteristic (ROC) Curve (AUC) ranging between 0.89 and 0.96 . However, use of these would be impractical in routine primary care because of the substantial number of variables in several scores; and also because many of the clinical signs have considerable inter-observer variation even amongst specialists (raised JVP, third heart sound, hepatojugular reflux). ${ }^{\text {w35,w36 }}$ Furthermore four of the scores include specific chest x-ray parameters difficult to apply in general practice.

A recent meta-analysis using individual patient data identified a simple new diagnostic score. This rule suggests that in a patient presenting with new symptoms such as breathlessness in whom heart failure is suspected, if the patient has any one of: a) history of MI OR b) basal crepitations OR c) is a male with ankle oedema (so called MICE score), then it is appropriate to refer straight for echocardiography as the probability of heart failure is high. Otherwise, a plasma BNP test should be performed, and referral to echocardiography should be organised depending on the concentration of plasma BNP (Table 4). ${ }^{20}$

\section{Limitations of the evidence base}

There is no single ideal reference standard for heart failure, since there is no single cardiac disorder that accounts for the syndrome. The underlying cardiac disorders can be classified in different ways. The standard approach is to divide heart failure into low ejection fraction and normal ejection fraction heart failure, if significant valve disease has been excluded as the primary cause of the heart failure. Echocardiography is a suitable reference standard for low ejection fraction heart failure, but is not as robust for normal ejection fraction heart failure. The definitive tests to diagnose normal ejection fraction heart failure (pressure-volume measurements at cardiac catheterisation) are often not carried out, so the diagnosis usually relies upon clinical judgement and supportive evidence. 
Studies that have tested the value of the ECG in the diagnosis of heart failure have used different criteria with which to define abnormality, and there has been variation in the experience and expertise of the person reading the ECG. Many general practitioners are unable to interpret ECGs accurately.

For natriuretic peptides, most of the existing research has been done on secondary care populations, or in the context of screening studies that identify prevalent cases of heart failure, or include patients with existing diagnoses of heart failure. This may introduce significant spectrum bias and affect whether the cut-off values are reliable for the target population, namely symptomatic patients presenting in primary care.

\section{Conclusions}

Heart failure is a clinical syndrome that may be difficult for a primary care physician to diagnose accurately, particularly if the symptoms develop slowly and are not so severe as to warrant immediate hospitalisation. Access to tests that can help rule out heart failure (such as plasma BNP or NT-proBNP) when combined with clinical assessment can be very useful to aid the physician's investigation pathway. Patients likely to have heart failure after such initial assessment should undergo echocardiography, with expert interpretation, to help confirm the diagnosis and to determine the underlying cardiac pathophysiology. More detailed diagnostic work-up may also be required to fully characterise the syndrome and determine the appropriate management plan.

\section{Competing I nterests of Authors:}

FDRH has received research funding from Roche Diagnostics, and occasional speaker fees and symposia expenses from Roche and Bayer Diagnostics. J M chairs the NICE Heart Failure Guidelines committee. MC has provided consultancy advice to, and occasional speaking fees from, Stirling Medical and Roche Diagnostics. No author has stock or shares in any device or assay company. 
The Corresponding Author has the right to grant on behalf of all authors and does grant on behalf of all authors, an exclusive licence (or non exclusive for government employees) on a worldwide basis to the BMJ Publishing Group Ltd to permit this article (if accepted) to be published in J NL and any other BMJ PGL products and sublicences such use and exploit all subsidiary rights

\section{Main Points}

- Heart failure is difficult to diagnose in primary care

- Early diagnosis can favourably alter prognosis and mortality

- A number of symptoms and signs have some diagnostic value in the clinical assessment of a patient with suspected heart failure. Dyspnoea is the symptom with the highest sensitivity, but it is not sufficiently high that heart failure can be ruled out in its absence

- ECG, BNP and NT-proBNP all have high sensitivity for heart failure

- Head-to-head studies and systematic reviews suggest that BNP or NT-proBNP is a more accurate investigation than ECG for the diagnosis of heart failure.

- There is no evidence that performing both BNP and ECG improves diagnosis of heart failure

- There is no evidence of any significant difference in accuracy between different BNP assays

- A simple clinical score based upon gender, history of MI, presence of oedema and presence of basal lung crepitations may help a physician discriminate between people with suspected heart failure who should be referred straight for echocardiography, and people for whom the diagnosis is less likely and should be confirmed by a BNP test before referral. 
Table 1. Definition of heart failure in the current ESC guidelines for the diagnosis and management of heart failure. ${ }^{17}$

Heart failure is a syndrome in which patients have the following features:

- Symptoms typical of heart failure

(breathlessness at rest or on exertion, fatigue, tiredness, ankle swelling)

AND

- $\quad$ Signs typical of heart failure

(tachycardia, tachypnoea, pulmonary rales, pleural effusion, raised jugular venous pressure, peripheral oedema, hepatomegaly)

AND

- Objective evidence of a structural or functional abnormality of the heart at rest (cardiomegaly, third heart sound, cardiac murmur, abnormality on the echocardiogram, raised natriuretic peptide concentration) 
Table 2. Overall accuracy of clinical features of heart failure.

\begin{tabular}{|l|c|c|c|c|}
\hline & $\begin{array}{c}\text { Number of Patients } \\
\text { (studies) }\end{array}$ & Sensitivity (\%) & Specificity (\%) & Youden Index* \\
\hline History of AMI & $1769(10)$ & 26 & 89 & 15 \\
\hline Dyspnoea & $2187(5)$ & 87 & 51 & 38 \\
\hline Orthopnoea & $2901(6)$ & 44 & 89 & 33 \\
\hline $\begin{array}{l}\text { Paroxysmal } \\
\text { nocturnal dyspnoea }\end{array}$ & $1786(3)$ & \multicolumn{3}{|c|}{ No summary results } \\
\hline Oedema & $3736(12)$ & 53 & 72 & 25 \\
\hline Tachycardia & $1582(3)$ & 52 & 70 & 22 \\
\hline Elevated JP & $3353(7)$ & 27 & 99 & 12 \\
\hline Cardiomegaly & $405(1)$ & 11 & 81 & 32 \\
\hline Added heart sounds & $2948(6)$ & 51 & 97 & 14 \\
\hline Lung crepitation & $4619(11)$ & 17 & \multicolumn{3}{|l|}{} \\
\hline Hepatomegaly & $1058(1)$ & &
\end{tabular}

* Youden index $=$ Sensitivity $\%+$ specificity $\%-100 \%$. This is a measure of the overall diagnostic accuracy of the test, with a maximum score of 100; AMI = Acute Myocardial Infarction

Table 3. Overall accuracy of investigations for heart failure.

\begin{tabular}{|l|c|c|c|c|}
\hline & $\begin{array}{c}\text { Number of Patients } \\
\text { (studies) }\end{array}$ & Sensitivity (\%) & Specificity (\%) & Youden Index* \\
\hline ECG & $4702(11)$ & $89 \%$ & $56 \%$ & 45 \\
\hline $\begin{array}{l}\text { CXR: any } \\
\text { abnormality increased }\end{array}$ & $2323(5)$ & $68 \%$ & $83 \%$ & 51 \\
\hline $\begin{array}{l}\text { CXR: } \\
\text { Cardio-thoracic ratio }\end{array}$ & $4797(6)$ & $67 \%$ & $76 \%$ & 43 \\
\hline BNP (20) & $4229(16)$ & $93 \%$ & $74 \%$ & 67 \\
\hline NT-proBNP & $93 \%$ & $65 \%$ & 58 \\
\hline
\end{tabular}

- Youden index $=$ Sensitivity $\%+$ specificity $\%-100 \%$. This is a measure of the overall diagnostic accuracy of the test; ECG + Electrocardiograph; CXR = Chest X Ray; BNP and NTproBNP $=\mathrm{B}$ Type natriuretic peptide and $\mathrm{N}$ Terminal pro $\mathrm{B}$ Type natriuretic peptide 
Table 4. Simple clinical decision rule (MICE) developed in a UK Health Technology Assessment for the diagnosis of heart failure in primary care. ${ }^{20}$

\section{Clinical rule}

In a patient presenting with symptoms in whom heart failure is suspected, refer straight to echocardiography if the patient has any one of:

- history of MI , or

- basal crepitations, or

- male with ankle oedema

Otherwise, carry out a BNP test, and refer for echocardiography depending on the results of the BNP:

- Female without ankle oedema - refer for echocardiography if BNP $>210-360 \mathrm{pg} / \mathrm{ml}$ depending upon local availability of echocardiography (or NTproBNP $>620-1060 \mathrm{pg} / \mathrm{ml}$ )

- Male without ankle oedema - refer for echocardiography if BNP > 130-220 pg/ml (or NT-proBNP $>390-660 \mathrm{pg} / \mathrm{ml}$ )

- Female with ankle oedema - refer for echocardiography if BNP > 100-180 pg/ml (or NT-proBNP $>190-520 \mathrm{pg} / \mathrm{ml}$ )

$\mathrm{MI}=$ Myocardial Infarction

BNP and NT-proBNP = B Type natriuretic peptide and N Terminal pro B Type natriuretic peptide 
Figure 1. Diagnostic algorithm recommended for use in primary care by the National Institute for Health and Clinical Excellence in England, 2003. ${ }^{18}$

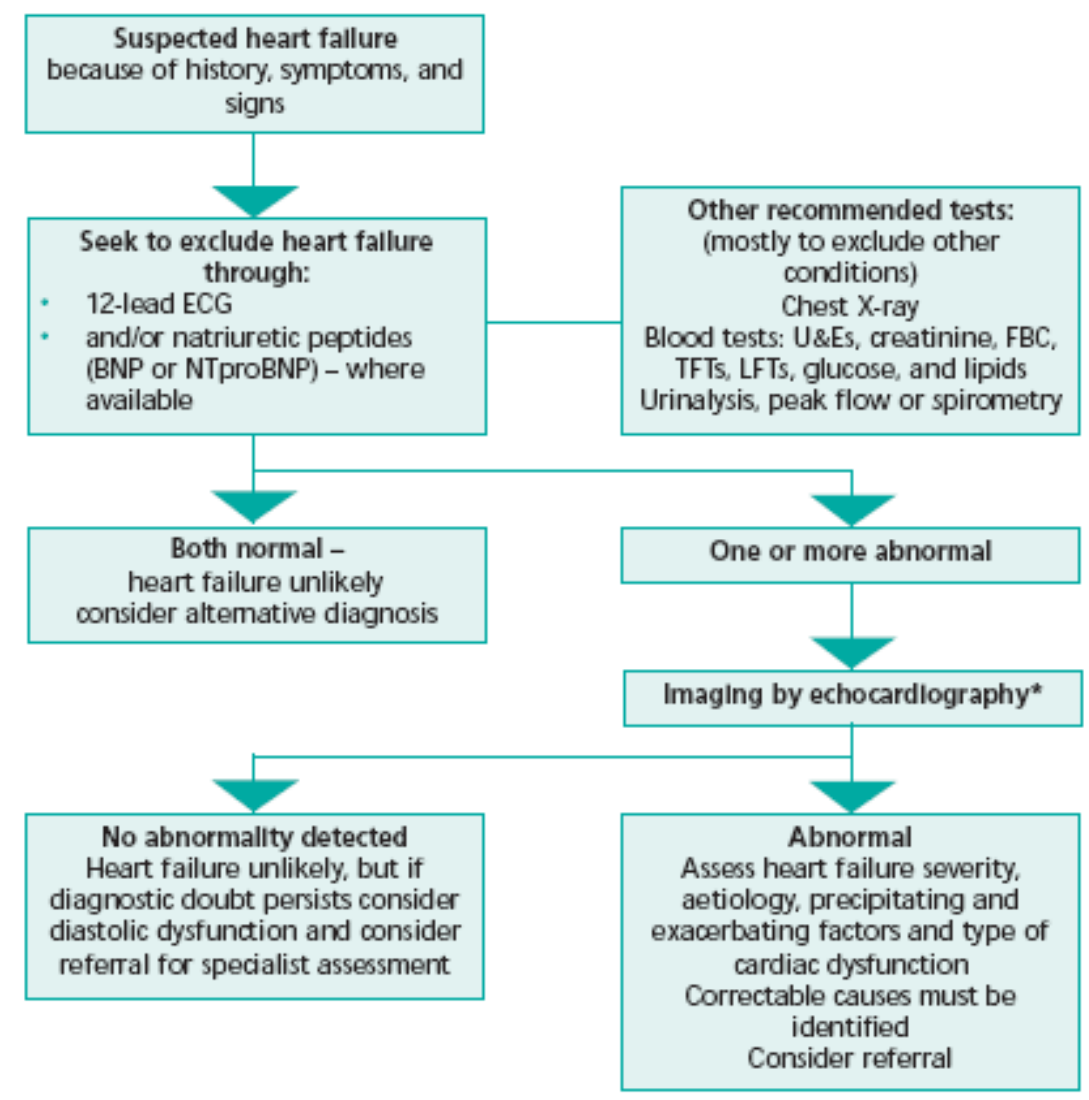

- Alternative methods of imaging the heart should be considered when a poor image is produced by transthoracic Doppler 2D echocardiography - alternatives include transoesophagal Doppler 2D echocardiography, radionuclide imaging or cardiac magnetic resonance imaging

\begin{tabular}{|ll|}
\hline Key: & \\
BNP & B-type natriuretic peptide \\
ECG & Electrocardiogram \\
FBC & Full blood count \\
LFTs & Liver function tests \\
NTproBNP & N-terminal pro-B-type natriuretic peptide \\
TFTs & Thyroid function tests \\
U\&Es & Urea and electrolytes \\
\hline
\end{tabular}




\section{MCQs}

Heart failure prognosis is

1) generally good

2) worse for patients diagnosed in primary care than in hospital

3) not linked to disease stage

4) improved by ACE inhibitors and beta blocker therapies

5) worsening across the population over time

In the diagnosis of heart failure

1) typical signs and symptoms are sufficiently reliable to establish disease

2) ECG is sufficiently reliable to establish disease

3) CXR is sufficiently reliable to establish disease

4) natriuretic peptide assays are more reliable than ECG

5) echocardiography is better for diagnosing preserved systolic function (diastolic) heart failure than for left ventricular systolic dysfunction heart failure

Heart failure

1) prevalence is between $2-3 \%$ of the adult population

2) incidence is greater in women than men

3) incidence and prevalence are predicted to fall

4) prevalence is less certain for LVSD heart failure

5) prevalence is lower in countries with high rates of coronary heart disease

When considering natriuretic peptides

1) they are fully evaluated in terms of their utility in heart failure diagnosis

2) the cut-offs are the same for BNP and NT-proBNP assays

3) both BNP and NT-proBNP are equally reliable in heart failure diagnosis

4) adding an ECG to the assays adds incremental value

5) they have no other value than in heart failure diagnosis

The MICE clinical decision rule for heart failure diagnosis states

1) refer for echocardiograpy, all women with BNP $>210 \mathrm{pg} / \mathrm{ml}$ (NT-proBNP $>620 \mathrm{pg} / \mathrm{ml}$ )

2) refer for echocardiography, all men with suspected heart failure

3) refer for echocardiography, all men suspected of heart failure with ankle oedema

4) test for natriuretic peptides, women suspected of heart failure with past myocardial infarction

5) test for natriuretic peptides, men with basal crepitations

In the diagnosis of heart failure

1) most guidelines advocate an echocardiographic left ventricular ejection fraction cut-off of $<50 \%$ to determine heart failure

2) the utilisation of echocardiography testing across Europe is high

3) cardiac imaging is advocated for aetiology and staging even in those patients with confirmed diagnoses

4) early diagnosis will not alter disease progression since no treatments delay progression

5) echocardiography is a fully quantitative investigation 


\section{References}

${ }^{1}$ Gillum RF. Epidemiology of heart failure in the United States. Am Heart J 1993; 126: 1042-1047

${ }^{2}$ O'Connell JB, Bristow MR. Economic impact of heart failure in the United States: time for a different approach. J Heart Lung Transplant 1994; 13 (Suppl 4):S107-S112

3 Hobbs FDR, Roalfe AK, Davis RC, Davies MK, Hare R. Prognosis of all-cause heart failure and borderline left ventricular systolic dysfunction: 5 year mortality follow-up of the Echocardiographic Heart of England Screening Study (ECHOES). European Heart J ournal 2007; 28: 1128-34

Useful recent mortality data that encompass outcomes in all grades (mild to severe) of heart failure in a prior screened UK population

4 McKee PA. Castelli WP, McNamara PM, Kannell WB. The natural history of heart failure: The Framingham Study. N Engl J Med 1971; 285: 1441-6

${ }^{5}$ Ho KKL, Pinsky JL, Kannel WB. The epidemiology of heart failure: The Framingham study. J Am Cardiol 1993; 22 (Supp A): 6A-13A

6 McDonagh TA, Morrison CE, Lawrence A, Ford I, Tunstall-Pedoe H, McMurray JJV, Dargie HJ. Symptomatic and asymptomatic left ventricular systolic dysfunction in an urban population. Lancet 1997; 350: 829-33

${ }^{7}$ Morgan S, Smith H, Simpson I, Liddiard GS, Raphael H, Pickering RM, Mant D. Prevalence and clinical characteristics of left ventricular dysfunction among elderly patients in general practice setting: cross sectional survey. BMJ 1999; 318: 368-72

${ }^{8}$ Davies MK, Hobbs FDR, Davis RC, Kenkre JE, Roalfe AK, Hare R et al. Prevalence of left ventricular systolic dysfunction and heart failure in the general population: main findings from the ECHOES (Echocardiographic Heart of England Screening) Study. Lancet 2001; 358: 439-445

The largest of the UK heart failure cohorts identified by random population screening

${ }^{9}$ Cowie MR, Wood DA, Coats A, et al. Incidence and aetiology of heart failure: a population-based study. Eur Heart J 1999; 20: 421-428

The best estimates on the current incidence of heart failure in the UK

10 Cleland J G, Swedberg K, Follath F, Komajda M, Cohen-Solal A, Aguilar JC, Dietz R, Gavazzi A, Hobbs R, Korewicki J, Madeira HC, Moiseyev VS, Preda I, van Gilst WH, Widimsky J, Freemantle N, Eastaugh J, Mason J; Study Group on Diagnosis of the Working Group on Heart Failure of the European Society of Cardiology. The EuroHeart Failure survey programme - a survey on the quality 
of care among patients with heart failure in Europe Part 1: patient characteristics and diagnosis. Eur Heart J 2003: 24; 442-463

${ }^{11}$ Garg R, Yusuf S, for the Collaborative Group on ACE Inhibitor Trials. Overview of randomized trials of angiotensin-converting enzyme inhibitors on mortality and morbidity in patients with heart failure. JAMA 1995; 273: 1450-56

The pooled data for the effectiveness of ACE inhibitors in heart failure

${ }^{12}$ Lechat P, Packer M, Chalon S, Cucherat M, Arab T, Boissel JP. Beta-blockers in heart failure: metaanalysis of randomized trials. Circulation 1998; 98: 1184-91

Pooled data on the effectiveness of B blockers in heart failure

13 American College of Cardiology/ American Heart Association. Guidelines for the evaluation and management of heart failure. Report of the American College of Cardiology/American Heart Association Task Force on Practice Guidelines (Committee on Evaluation and Management of Heart failure) Circulation 1995; 92: 2764-27

${ }^{14}$ Clarke KW, Gray D, Hampton JR. Evidence of inadequate investigation and treatment of patients with heart failure. Br Heart J 1994; 71: 584-587

15 Hunt SA, Abraham WT, Chin MH, Feldman AM, Francis GS, Ganiats TG, et al. ACC/AHA 2005 Guideline Update for the Diagnosis and Management of Chronic Heart Failure in the Adult: A Report of the American College of Cardiology/American Heart Association Task Force on Practice Guidelines (Writing Committee to Update the 2001 Guidelines for the Evaluation and Management of Heart Failure): Developed in Collaboration With the American College of Chest Physicians and the International Society for Heart and Lung Transplantation: Endorsed by the Heart Rhythm Society. Circulation, 2005; 112: 154-235

The current main US guidelines for diagnosis and management of heart failure

16 HFSA guidelines: Heart Failure Society of America. Comprehensive Heart Failure Practice Guideline, 2006. J Cardiac Failure 2006; 12: e1-e122

17 Task Force for Diagnosis and Treatment of Acute and Chronic Heart Failure 2008 of European Society of Cardiology, Dickstein K, Cohen-Solal A, Filippatos G, McMurray JJ, Ponikowski P, PooleWilson PA, Strömberg A, van Veldhuisen DJ, Atar D, Hoes AW, Keren A, Mebazaa A, Nieminen M, Priori SG, Swedberg K; ESC Committee for Practice Guidelines, Vahanian A, Camm J, De Caterina R, Dean V, Dickstein K, Filippatos G, Funck-Brentano C, Hellemans I, Kristensen SD, McGregor K, Sechtem U, Silber S, Tendera M, Widimsky P, Zamorano J L. ESC Guidelines for the diagnosis and treatment of acute and chronic heart failure 2008: the Task Force for the Diagnosis and Treatment of 
Acute and Chronic Heart Failure 2008 of the European Society of Cardiology. Developed in collaboration with the Heart Failure Association of the ESC (HFA) and endorsed by the European Society of Intensive Care Medicine (ESICM). Eur Heart J. 2008; 29 (19): 2388-442

The most recent ESC guidance on the diagnosis of heart failure

${ }^{18}$ National Collaborating Centre for Chronic Conditions on behalf of the National Institute for Clinical Excellence. Chronic heart failure: management of chronic heart failure in adults in primary and secondary care. Salisbury. Royal College of Physicians 2003.

http://www.rcplondon.ac.uk/pubs/books/chf/heartfailure.pdf

The current NICE heart failure guidelines on diagnosis and management, though the revised update is due sometime in 2010

${ }^{19}$ Hobbs FDR, Davis RC, Roalfe AK, Hare R, Davies MK, Kenkre JE. Reliability of N-terminal pro-brain natriuretic peptide assay in diagnosis of heart failure: cohort study in representative and high risk community populations. BMJ 2002; 324:1498-1503

${ }^{20}$ Mant J, Doust J, Roalfe A, Barton P, Cowie M, Glasziou P, Mant D, McManus R, Holder R, Deeks J, Fletcher K, Qume M, Sohanpal S, Sanders S, Hobbs FDR. Systematic Review and Individual Patient Data Meta-analysis of Diagnosis of Heart Failure, with Modelling of Implications of Different Diagnostic Strategies in Primary Care. Health Technology Assessment, 2009; 13 (32): 1-207, iii. The most recent systematic review on the diagnostic options for heart failure which includes an IPD meta-analysis on the utility of BNP testing

${ }^{21}$ Mueller C, Scholer A, Laule-Kilian K, Martina B, Schindler C, Buser P, Pfisterer M, Perruchoud AP. Use of B-type natriuretic peptide in the evaluation and management of acute dyspnoea. $\mathrm{N}$ Engl J Med 2004; 350: 647-5

22 Doust JA, Glasziou PP, Pietrzak E, Dobson AJ. A systematic review of the diagnostic accuracy of natriuretic peptides for heart failure. Arch Intern Med 2004; 164: 1978-1984.

23 Doust J A, Saunders S, Pirozzo S, Francis D, Pietrzak E, Del Mar C, Glasziou P. National Institute of Clinical Studies. The diagnosis and recognition of congestive cardiac failure. Prepared by the Centre for Evidence Based Practice, University of Queensland, NICS, Melbourne 2002.

${ }^{24}$ Bradbury CJ, Cummins E, Downie S, Foster L, Stout A. The use of B-type natriuretic peptides in the investigation of patients with suspected heart failure. NHS Quality Improvement Scotland, May 2005.

${ }^{25}$ Khunti K, Squire I, Abrams KR, Sutton AJ. Accuracy of a 12-lead electrocardiogram in screening patients with suspected heart failure for open access echocardiography: a systematic review and meta-analysis. European J ournal of Heart Failure 2004; 6:571-576. 
Davie AP, Francis CM, Love MP, Caruana L, Starkey IR, Shaw TRD, Sutherland GR, McMurray JJV. Value of an electrocardiogram in identifying heart failure due to left ventricular systolic dysfunction. British Medical J ournal 1996; 312: 222

27 The NETWORK Investigators: Clinical outcome with enalapril in symptomatic chronic heart failure; a dose comparison. Eur Heart 1998; 19: 481-489

${ }^{28}$ Davenport C, Cheng EYL, Kwok YTT et al. Assessing the diagnostic test accuracy of natriuretic peptides and ECG in the diagnosis of left ventricular systolic dysfunction: a systematic review and meta-analysis. British J ournal of General Practice 2006; 56:48-56.

${ }^{29}$ Latour-Perez J, Coves-Orts FJ, Abad-Terrado C, Abraira V, Zamora J et al. Accuracy of B-type natriuretic peptide levels in the diagnosis of left ventricular dysfunction and heart failure: a systematic review. European Journal of Heart Failure 2006; 8:390-399

${ }^{30}$ Cardarelli R, Lumicao TG. B type natriuretic peptide: a review of its diagnostic, prognostic, and therapeutic monitoring value in heart failure for primary care physicians. J Am Board Fam Pract 2003; 16:327-333.

31 Korenstein D, Wisnivesky JP, Wyer P, Adler R, Ponieman D, McGinn T. The utility of B type natriuretic peptide in the diagnosis of heart failure in the emergency department: a systematic review. BMC Emergency Medicine 2007; 7:6

32 Battaglia M, Pewsner D, Juni P, Eger M, Bucher HC, Bachmann LM. Accuracy of B-type natriuretic peptide tests to exclude congestive heart failure. Arch Intern Med 2006; 166: 1073-80.

${ }^{33}$ Paulus WJ, Tschope C, Sanderson JE et al. How to diagnose diastolic heart failure: a consensus statement on the diagnosis of heart failure with normal left ventricular ejection fraction by the Heart Failure and Echocardiography Associations of the European Society of Cardiology. Eur Heart J 2007;

28: $2539-2550$

Consensus guidelines on the diagnosis of preserved systolic function heart failure

${ }^{34}$ Mosterd A, Deckers JW, Hoes AW et al. Classification of heart failure in population based research: an assessment of six heart failure scores. European J ournal of Epidemiology 1997; 13: 491-502

${ }^{35}$ Gadsboll N, Hoilund-Carlsen PF, Nielsen GG, Berning J, Brunn NE, Stage P, et al. Symptoms and signs of heart failure in patients with myocardial infarction: reproducibility and relationship to chest X-ray, radionuclide ventriculography and right heart catheterization. Eur Heart J 1989; 10: 1017-1028

36 Lok CE, Morgan CD, Ranganathan N. The accuracy and inter-observer agreement in detecting 'gallop sounds' by cardiac auscultation. Chest 1998; 114: 1283-1288 